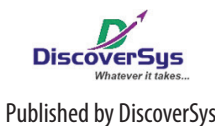

Published by DiscoverSys

\section{Factors Associated with Rabies Dog Vaccination Practices in Bebandem}

\author{
I Nyoman Sudiatmika, ${ }^{1,2^{*}}$ Dewa Nyoman Wirawan, ${ }^{2}$ Made Pasek Kardiwinata ${ }^{2,3}$
}

\section{ABSTRACT}

Background and purpose: The first reported case of rabies in Bali was in November 2008, wherein previously in Bali was declared rabies free. The epidemic spread rapidly to all district, including Karangasem regency. By December 2015 there were 163 reported rabies cases and all of them were infected through dog bites. It was estimated that there were 411,153 domestic canines in Bali. From 2009-2015 the immunization coverage in dog was reported $55.0-76.9 \%$. This study aims to determine the proportion of households in the district of Bebandem that have vaccinated their dogs and the factors that influence the decision to vaccinate.

Methods: The study was cross sectional and carried out in two villages in the district Bebandem with a sample of 110 families randomly selected. Data was collected through interviews regarding socio-demographic variables, knowledge, attitudes, perceptions, types of vaccination facilities, distance from vaccination facility and information received from the Departement of Agriculture/head of village. Multivariate analysis was done using poisson regression to determine the relationship between these variables with their dog vaccination for rabies.

Results: Results indicated that $88 \%$ of households vaccinated their canine pets. Multivariate analysis showed that factors associated with the administration of the rabies vaccines were: having attended education session ( $\mathrm{APR}=2.37 ; 95 \% \mathrm{Cl}$ : $1.34-4.18)$; family income $(A P R=1.16 ; 95 \% C l: 1.03-1.31)$; and perception (APR=3.09; 95\%Cl: 1.20-7.97). There was no significant relationship between education, knowledge and attitudes towards rabies vaccination in dog.

Conclusion: Factors associated with dog rabies vaccination practice were having attended education session, family income and perception.

Keywords: Dog rabies vaccination, behavior, Karangasem Bali

Cite This Article: Sudiatmika, I.N., Wirawan, D.N., Kardiwinata, M.P. 2016. Factors Associated with Rabies Dog Vaccination Practices in Bebandem. Public Health and Preventive Medicine Archive 4(2): 120-125. D01:10.15562/phpma.v4i2.68

\title{
Faktor yang Berhubungan dengan Praktik Pemberian Vaksinasi Rabies Anjing di Kecamatan Bebandem
}

${ }^{1}$ Karangasem Health Office,

${ }^{2}$ Public Health Postgraduate Program Udayana University,

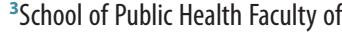
Medicine Udayana University

*Correspondence to:

I Nyoman Sudiatmika, Karangasem Health Office

nym.sudiatmika42@yahoo.com jenis fasilitas pelayanan vaksinasi, jarak pelayanan vaksinasi, himbauan petugas peternakan/kepala desa dan penyuluhan yang diterima. Analisis multivariat dilakukan dengan regresi poisson untuk mengetahui hubungan antara variabel-variabel di atas dengan pemberian vaksin. Hasil: Hasil penelitian menunjukkan $88 \%$ rumah tangga telah memberikan vaksinasi pada anjingnya. Hasil analisis multivariat menunjukkan bahwa faktor yang berhubungan dengan pemberian vaksin rabies pada anjing adalah: pernah mengikuti penyuluhan (APR=2,37; 95\%Cl: 1,34-4,18); penghasilan keluarga (APR=1,16; 95\%Cl: 1,03-1,31) dan persepsi terhadap rabies (APR=3,09; 95\%Cl: 1,20-7,97). Dalam penelitian ini tidak dijumpai hubungan yang bermakna antara variabel pendidikan, pengetahuan dan sikap dengan vaksinasi rabies pada anjing. Simpulan: Faktor-faktor yang berhubungan dengan pemberian vaksinasi rabies pada anjing adalah pernah mengikuti penyuluhan, penghasilan keluarga dan persepsi. 


\section{PENDAHULUAN}

Rabies merupakan penyakit zoonosis yang menjadi masalah secara global karena sampai saat ini belum ditemukan cara pengobatannya dan case fatality rate mencapai $100 \% .{ }^{1} \mathrm{Di}$ Indonesia penyakit rabies endemis di 24 dari 33 provinsi. ${ }^{2}$ Hewan yang menularkan rabies di Indonesia pada umumnya adalah anjing dan berdasarkan data Depkes RI, pada tahun 2010 di Indonesia terjadi 62.031 kasus gigitan hewan penular rabies (GHPR) dengan 195 kematian. $^{2}$

Di Provinsi Bali kasus rabies pertama dilaporkan pada Bulan Nopember 2008, dimana sebelumnya Bali dinyatakan bebas rabies. ${ }^{6}$ Sejak saat itu epidemi rabies menyebar dengan cepat ke semua kabupaten di Propinsi Bali, termasuk Kabupaten Karangasem. Data dari Dinas Kesehatan Provinsi Bali menunjukkan bahwa pada tahun 2015 jumlah GHPR di Bali sebanyak 35.733 kasus dengan jumlah kematian pada manusia dari tahun 2009 sampai dengan 2015 sebanyak 163 orang. ${ }^{3}$ Jumlah GHPR di Kabupaten Karangasem pada tahun 2015 sebanyak 3.289 kasus dengan 43 kematian dan merupakan kabupaten dengan jumlah kematian tertinggi pada manusia karena rabies. Jumlah kasus rabies pada manusia tertinggi di Kabupaten Karangasem berada di Kecamatan Bebandem. Jumlah GHPR di Kecamatan Bebandem mengalami peningkatan dari tahun 2013 sampai dengan 2015, yaitu dari 477 kasus pada tahun 2013, menjadi 625 kasus pada tahun 2014 dan 721 kasus pada tahun 2015. Pada tahun 2009 sampai 2015 terdapat 11 kasus kematian akibat rabies di Kecamatan Bebandem. ${ }^{4}$

Berbagai upaya telah dilakukan pemerintah Provinsi Bali untuk menanggulangi penyebaran penyakit rabies, diantaranya dengan melakukan vaksinasi pada anjing. Pengendalian penyakit rabies sangat ditentukan oleh cakupan vaksinasi yang sekurang-kurangnya sebanyak $70 \%$ dan pengendalian populasi anjing. ${ }^{5}$ Data dari Dinas Peternakan Kabupaten Karangsem menyatakan bahwa pada tahun 2015 jumlah anjing di Karangasem diperkirakan mencapai 37.648 ekor, dengan cakupan vaksinasi sebesar $65 \% .{ }^{6}$ Cakupan vaksinasi dan pengendalian hewan penular rabies khususnya anjing tidak hanya ditentukan oleh peran pemerintah tetapi juga oleh peran masyarakat dan faktor lingkungan.?

Hasil penelitian sebelumnya menyatakan bahwa faktor yang mempengaruhi cakupan vaksinasi rabies pada anjing adalah: faktor sosiodemografi, predisposisi, pemungkin dan penguat..$^{8-12}$ Penelitian ini bertujuan mengetahui faktor-faktor yang berhubungan dengan vaksinasi rabies pada anjing di Kecamatan Bebandem Kabupaten Karangasem.

\section{METODE}

Rancangan penelitian adalah survei cross-sectional yang dilakukan pada Bulan Januari sampai dengan Oktober 2015 di Desa Bebandem dan Desa Buana Giri, Kecamatan Bebandem, Kabupaten Karangasem. Jumlah sampel sebanyak 110 kepala keluarga yang memiliki anjing dan bersedia menjadi responden. Pemilihan sampel dilakukan secara acak sistematik dari daftar pemilik anjing di Desa Bebandem dan Buana Giri.

Data yang dikumpulkan adalah pemberian vaksin rabies pada anjing, variabel sosio-demografi, pengetahuan, sikap, persepsi, jenis fasilitas pelayanan vaksinasi, jarak pelayanan vaksinasi, himbauan petugas peternakan, himbauan kepala desa/tokoh masyarakat dan pernah mengikuti penyuluhan. Data dikumpulkan dengan wawancara di rumah masing-masing responden. Analisis data dilakukan secara univariat, bivariat dan multivariat menggunakan regresi poisson dengan STATA 12.1. Variabel yang berhubungan dengan vaksinasi rabies pada anjing dengan nilai $\mathrm{p}<0,05$ diikutkan dalam analisis multivariat. Penelitian ini telah mendapat kelaikan etik dari Komisi Etik Fakultas Kedokteran Universitas Udayana/Rumah Sakit Umum Pusat Sanglah Denpasar.

\section{HASIL}

Pada Tabel 1 terlihat bahwa 57,3\% responden berumur 25-49 tahun, 72,7\% berjenis kelamin laki-laki, 63,6\% berpendidikan SMP ke bawah, 93,9\% memiliki penghasilan keluarga cukup (diatas UMK) dan $70,0 \%$ bekerja sebagai petani, peternak, buruh, tukang dan dagang.

Pada Tabel 2 disajikan hasil analisis bivariat variabel yang berhubungan dengan vaksinasi rabies pada anjing berdasarkan umur, jenis kelamin, pekerjaan, pendidikan, penghasilan, pengetahuan, sikap, persepsi, himbauan petugas peternakan, himbauan kepala desa/toma dan penyuluhan yang diikuti. Terlihat bahwa variabel yang bermakna secara statistik $(\mathrm{p}<0,05)$ berhubungan dengan vaksinasi rabies adalah penghasilan, pengetahuan, sikap, persepsi dan pernah mengikuti penyuluhan. Responden yang memberikan vaksin pada anjing peliharaannya dijumpai lebih banyak pada keluarga yang berpenghasilan rendah (dibawah UMK) yaitu sebanyak $74,0 \%$, memiliki pengetahuan baik $(89,3 \%)$, sikap positif $(87,5 \%)$, persepsi baik $(90,4 \%)$ dan pernah mengikuti penyuluhan $(94,2 \%)$.

Pada Tabel 3 disajikan hasil analisis multivariat variabel yang berhubungan dengan vaksinasi rabies. Variabel yang secara statistik bermakna berhubungan dengan vaksinasi rabies adalah: penghasilan keluarga, persepsi dan pernah 
Tabel 1 Karakteristik responden di Desa Bebandem dan Buana Giri di Kecamatan Bebandem Tahun 2015

\begin{tabular}{lll}
\hline Karakteristik responden & $\mathbf{n}$ & $\%$ \\
\hline Umur (tahun) & 4 & 3,64 \\
$15-24$ & 63 & 57,27 \\
$25-49$ & 43 & 39,09 \\
$\geq 50$ & & 72,73 \\
Jenis kelamin & 80 & 27,27 \\
$\quad$ Laki-laki & 30 & 63,64 \\
$\quad$ Perempuan & & 36,36 \\
Pendidikan & 70 & \\
$\quad \leq$ SMP & 40 & 20,91 \\
$\geq$ SMA & & 70,00 \\
Pekerjaan & 23 & 9,09 \\
$\quad$ PNS/TNI/POLRI/pegawai swasta & 77 & \\
$\quad$ Petani/peternak/buruh/tukang/dagang & 10 & 70,00 \\
Lainnya (IRT/pegawai kontrak) & & 30,00 \\
Penghasilan keluarga & 77 & $100 \%$ \\
Cukup (diatas UMK Karangasem) & 33 & \\
$\quad$ Rendah (dibawah UMK Karangasem) & 110 & \\
Jumlah & & \\
\hline
\end{tabular}

Tabel 2 Variabel yang berhubungan dengan praktik pemberian vaksinasi rabies anjing di Kecamatan Bebandem Tahun 2015

\begin{tabular}{lccc}
\hline & \multicolumn{2}{c}{ Pemberian vaksin } & \\
\cline { 2 - 3 } Variabel & Ya & Tidak & Nilai p \\
\hline Umur (tahun) & $4(100,00)$ & $0(0,00)$ & \\
$15-24$ & $48(76,19)$ & $15(23,81)$ & 0,378 \\
$24-49$ & $36(83,72)$ & $7(16,28)$ & \\
$\geq 50$ & & & \\
Jenis kelamin & $63(78,75)$ & $17(21,25)$ & 0,592 \\
$\quad$ Laki-laki & $25(83,33)$ & $5(16,67)$ & \\
$\quad$ Perempuan & & & \\
Pekerjaan & $20(86,96)$ & $1(13,04)$ & \\
$\quad$ PNS/TNI/POLRI/pegawai swasta & $60(77,92)$ & $17(22,08)$ & \\
$\quad$ Petani/peternak/buruh/tukang/dagang & $8(80,00)$ & $2(20,00)$ & \\
$\quad$ Lainnya (IRT/pegawai kontrak) & & & \\
Pendidikan & $53(75,71)$ & $17(24,29)$ & \\
$\quad$ SSMP & $35(87,50)$ & $5(12,50)$ & \\
$\quad \geq$ SMA & & & \\
Penghasilan keluarga & $57(74,03)$ & $20(25,97)$ & 0,017 \\
$\quad$ Rendah & $31(93,94)$ & $2(6,06)$ & \\
$\quad$ Cukup & & $6(10,71)$ & \\
Pengetahuan & $50(89,29)$ & $16(29,63)$ & \\
$\quad$ Baik & $38(70,37)$ & & \\
$\quad$ Kurang & & & \\
\hline
\end{tabular}




\begin{tabular}{|c|c|c|c|}
\hline \multirow[b]{2}{*}{ Variabel } & \multicolumn{2}{|c|}{ Pemberian vaksin } & \multirow[b]{2}{*}{ Nilai p } \\
\hline & Ya & Tidak & \\
\hline \multicolumn{4}{|l|}{ Sikap } \\
\hline Baik & $77(87,50)$ & $11(12,50)$ & \multirow{2}{*}{0,001} \\
\hline Kurang & $11(50,00)$ & $11(50,00)$ & \\
\hline \multicolumn{4}{|l|}{ Persepsi } \\
\hline Baik & $85(90,43)$ & $9(9,57)$ & \multirow{2}{*}{0,001} \\
\hline Kurang & $3(18,75)$ & $13(81,25)$ & \\
\hline \multicolumn{4}{|c|}{ Himbauan petugas peternakan } \\
\hline Setuju & $80(80,00)$ & $20(20,00)$ & \multirow{2}{*}{1,000} \\
\hline Tidak setuju & $8(80,00)$ & $2(20,00)$ & \\
\hline \multicolumn{4}{|c|}{ Himbauan kades/toma } \\
\hline Setuju & $80(80,00)$ & $20(20,00)$ & \multirow{2}{*}{1,000} \\
\hline Tidak setuju & $8(80,00)$ & $2(20,00)$ & \\
\hline \multicolumn{4}{|c|}{ Pernah mengikuti penyuluhan } \\
\hline $\mathrm{Ya}$ & $81(94,19)$ & $5(5,81)$ & \multirow{2}{*}{0,001} \\
\hline Tidak & $7(29,17)$ & $17(70,83)$ & \\
\hline
\end{tabular}

Tabel 3 Hasil analisis multivariat variabel yang berhubungan dengan praktek pemberian vaksinasi rabies anjing di Kecamatan Bebandem Tahun 2015

\begin{tabular}{lcccc}
\hline & & \multicolumn{2}{c}{$\mathbf{9 5} \mathbf{\% C l}$} & \multirow{2}{*}{ Nilai p } \\
\cline { 2 - 4 } Variabel & Adjusted PR & Lower & Upper & 0,871 \\
Pendidikan & 3,09 & 0,88 & 1,11 & 0,013 \\
Penghasilan keluarga & 1,16 & 1,03 & 1,31 & 0,106 \\
Pengetahuan & 1,11 & 0,97 & 1,25 & 0,374 \\
Sikap & 1,12 & 0,87 & 1,44 & 0,020 \\
Persepsi & 3,09 & 1,20 & 7,97 & 0,003 \\
Penyuluhan & 2,37 & 1,34 & 4,18 & \\
\hline
\end{tabular}

mengikuti penyuluhan. Responden yang mempunyai penghasilan cukup 1,2 kali mempunyai peluang untuk memberikan vaksin rabies pada anjing peliharaan (APR=1,16; 95\%CI: 1,03-1,31), sedangkan responden yang mempunyai persepsi baik 3,1 kali mempunyai peluang untuk memberikan vaksin rabies pada anjing peliharaan (APR=3,09; 95\%CI: 1,20-7,97) dan responden yang pernah mendapatkan penyuluhan 2,4 kali mempunyai peluang memberikan vaksin rabies pada anjing peliharaan (APR=2,37; 95\%CI: 1,34-4,18).

\section{DISKUSI}

Berdasarkan hasil analisis multivariat, penghasilan keluarga mempunyai hubungan yang signifikan dengan pemberian vaksinasi rabies pada anjing (APR $=1,16 ; 95 \%$ CI: 1,03-1,31). Hal ini sesuai dengan penelitian Efelina (2007) dan Yusra (2007) yang menyatakan bahwa penghasilan masyarakat pemilik anjing mempengaruhi tindakannya dalam pencegahan penyakit rabies. ${ }^{10,13}$ Pemilik anjing dengan penghasilan memadai cenderung memiliki sikap lebih baik dalam menjaga kesehatan dan kesejahteraan hewannya termasuk melakukan vaksinasi. ${ }^{10,13}$

Pengamatan di lapangan pada saat pengumpulan data penelitian ini menunjukkan bahwa pada responden dengan penghasilan keluarga lebih rendah (dibawah UMK) juga memiliki partisipasi yang baik dalam memberikan vaksinasi rabies anjing peliharaannya. Berdasarkan hasil wawancara, sebagian responden dengan penghasilan di bawah UMK mengaku tidak keberatan mengeluarkan uang untuk biaya vaksinasi rabies anjingnya. Hal ini dikarenakan mereka lebih mengkhawatirkan apabila anjing peliharannya menggigit orang lain dan menularkan rabies maka biaya pengobatan korban gigitan anjing menjadi tanggung jawab pemilik anjing. Alasan lain dari beberapa 
responden, mereka mengaku khawatir terhadap anak mereka yang senang bermain dengan anjing peliharaan akan tertular penyakit rabies dari anjing peliharaannya apabila anjing tidak divaksinasi.

Berkaitan dengan variabel persepsi dalam penelitian ini dijumpai bahwa persepsi baik tentang pentingnya vaksinasi rabies meningkatkan peluang memberian vaksin pada anjing peliharaannya dengan (APR=3,09; 95\%CI: 1,20-7,97). Hasil penelitian ini menemukan masyarakat di Desa Bebandem dan Buana Giri memiliki persepsi yang baik mengenai pentingnya vaksinasi rabies anjing dalam upaya pencegahan penyakit rabies. Adanya ancaman penyakit rabies yang ditularkan oleh anjing mendorong warga desa untuk melakukan tindakan pencegahan yaitu dengan melakukan vaksinasi rabies pada anjing peliharaannya. Faktor lain adalah persepsi warga desa tentang manfaat pemberian vaksin pada anjing (perceived benefits) untuk mengurangi perasaan terancam terhadap rabies. ${ }^{14}$

Berkaitan dengan penyuluhan dijumpai bahwa warga yang telah memperoleh penyuluhan mempunyai peluang untuk memberikan vaksinasi pada anjingnya sebanyak 2,4 kali dibandingkan dengan yang tidak mendapatkan penyuluhan dengan $\mathrm{APR}=2,37$ (95\%CI: 1,34-4,18). Hasil ini sejalan dengan hasil penelitian Ganefa (2001) bahwa ketidakpatuhan pemilik anjing dalam memberikan vaksinasi rabies dipengaruhi oleh keterpaparan terhadap penyuluhan. ${ }^{8}$ Penyuluhan dapat meningkatkan pengetahuan, sikap dan tindakan warga Desa Bebandem dan Buana Giri dalam penanggulangan penyakit rabies. Penyuluhan sebagai salah satu sarana penyampaian informasi juga bertujuan memberi kesadaran diri, yaitu membuat seseorang bersikap lebih peka terhadap upaya-upaya pencegahan dan penanggulangan penyakit rabies. Dengan komunikasi yang lebih intensif antara petugas kesehatan dan masyarakatn, maka masyarakat dapat bersikap yang positif dalam penanggulangan rabies. Menurut Notoatmodjo (2010), keterpaparan terhadap sumber informasi sangat penting untuk meningkatkan pengetahuan dan sikap yang positif untuk mencegah terjadinya penyebaran penyakit. ${ }^{15}$

Kebiasaan masyarakat di Desa Bebandem dan Buana Giri yang lebih banyak memelihara anjing secara bebas atau tidak diikat dan tidak dikandangkan, karena dipakai sebagai penjaga rumah merupakan kendala dari program pembebasan rabies. Perilaku masyarakat pemilik anjing sangat berperan dalam upaya pencegahan rabies karena salah satu kendala yang dihadapi untuk penanggulangan rabies adalah kurangnya partisipasi dan kesadaran masyarakat di Desa Bebandem dan Buana Giri yang secara mandiri untuk datang memvaksinasi anjing peliharaannya ke pos rabies atau ke klinik swasta yang ada.

Dilihat dari pendidikan, sikap dan pengetahuan responden dalam penelitian ini diperoleh hasil bahwa tingkat pendidikan responden tidak berhubungan dengan pemberian vaksinasi rabies anjing. Hal ini sejalan dengan penelitian yang dilaksanakan oleh Simanjuntak (1991) di Kota Bangkok bahwa pendidikan pemilik anjing tidak ada hubungan dengan tindakannya dalam pemberian vaksinasi rabies anjing. ${ }^{16}$ Hasil penelitian ini sejalan dengan hasil penelitian Efelina (2007) dan Yusra (2007) yang menyatakan bahwa pengetahuan tidak berkaitan dengan perilaku pencegahan penyakit rabies. ${ }^{10,13}$

Berkaitan dengan sikap dalam penelitian ini sesuai dengan yang dilaporkan oleh Wattimena dan Suharyo (2010) yang menyatakan bahwa tidak ada hubungan antara sikap dalam pemeliharaan anjing dengan kejadian rabies pada anjing. ${ }^{17}$ Secara teoritis hal ini kemungkinan karena sikap responden yang baik tidak selalu tercermin dari dalam perilaku mereka.

Implikasi penelitian ini adalah perlunya penyuluhan yang intensif dan berkesinambungan dalam upaya untuk meningkatkan cakupan vaksinasi rabies pada anjing. Penelitian ini hanya dilakukan di Kecamatan Bebandem Kabupaten Karangasem dan karena itu hasilnya tidak bisa digeneralisir di wilayah lain di Bali atau di Indonesia.

\section{SIMPULAN}

Faktor yang mempengaruhi pemberian vaksinasi rabies anjing adalah penghasilan keluarga, persepsi responden tentang pentingnya vaksinasi rabies anjing dan pernah mengikuti penyuluhan tentang rabies oleh petugas. Variabel yang tidak bermakna mempengaruhi praktek pemberian vaksinasi rabies anjing adalah pendidikan, pengetahuan dan sikap.

\section{UCAPAN TERIMA KASIH}

Ucapan terima kasih penulis sampaikan kepada seluruh responden dan semua pihak yang telah mendukung dalam pelaksanaan dan penulisan penelitian ini.

\section{DAFTAR PUSTAKA}

1. Depkes RI. Penatalaksanaan Kasus Gigitan Hewan Tersangka/Rabies. Subdit Pengendalian Zoonosis. Jakarta: Dit PPBB, Ditjen PP \& PL; 2011.

2. Departemen Kesehatan RI. Kejadian Luar Biasa Rabies. Jakarta: Departemen Kesehata RI; 2010.

3. Dinas Kesehatan. Pelaksanaan Program Pemberantasan Penyakit Rabies di Bali. Denpasar: Dinas Kesehatan Propinsi Bali; 2015. 
4. Dinkes Kab. Karangasem. Laporan Kegiatan Penanggulangan dan Pengendalian Rabies. Amlapura: Dinkes Kab. Karangasem; 2015.

5. Dinas Peternakan, Kelautan, dan Pertanian. Pencegahan dan Penanggulangan Penyakit Ternak, Dinas Peternakan, Kelautan, dan Pertanian Kab. Karangasem. Amlapura: Dinas Peternakan, Kelautan, dan Pertanian 2014.

6. Putra. Bali Belum Bebas Rabies, 4500 Gigitan Anjing per Bulan. Fakultas Kedokteran Hewan UGM; 2012.

7. Naipospos, T.S. Vaksinasi Rutin Cegah Rabies: mungkinkah Indonesia. 2010. bebas? http:// tatvetblog.Blogspot. com/2010/03/vaksinasi-rutin-cegah-rabies-mungkinkah. html. Akses 9 Januari 2015.

8. Ganefa, Siti. Faktor-Faktor yang Berhubungan dengan Ketidakpatuhan Pemilik Anjing memberikan Vaksinasi Rabies pada Anjingnya di Kotip Cimahi, Kabupaten Bandung, Jawa Barat tahun 2000. Tesis. UI. Jakarta; 2001.

9. Hontong, O. Hubungan Pengetahuan dan Sikap masyarakat dengan Tindakan Pencegahan Rabies di Puskesmas Bengkol Kota Manado Tahun 2012.Skripsi. Manado: Fakultas Kesehatan Masyarakat Universitas Sam Ratulangi; 2012.

10. Lumbantoruan, Efelina. Pengaruh Karakteristik Individu Terhadap Tindakan Pemilik Anjing dalam Pencegahan Penyakit Rabies di Desa Namoriam Kecamatan Pancur Batu Kabupaten Deli Serdang Tahun 2007, Skripsi. Medan: USU; 2007.

11. Malahayati. E. Pengaruh Karakteristik Pemilik Anjing Terhadap Partisipasinya dalam Program Pencegahan Penyakit Rabies di Kelurahan Kwala Bekala Kecamaan Meda Johor Kota Medan; 2009.
12. Moningka, F. Hubungan antara pengetahuan dan Sikap Pemilik Anjing dengan Tindakan Pencegahan Rabies di Wilayah Kerja Puskesmas Ongkau Kabupaten Minahasa Selatan. Tesis. Program Pascasarjana Fakultas Kesehatan Masyarakat Universitas Sam Ratulangi Manado; 2013.

13. Yusra. Pengaruh Karakteristik Pemilik Anjing terhadap Tindakannya dalam Pencegahan Penyakit Rabies di Wilayah Kerja Puskesmas Muara Panas Kabupaten Solok Sumatera Barat Tahun 2007, Skripsi. Medan: USU; 2007.

14. Sarwono, S. Sosiologi Kesehatan, Beberapa Konsep Beserta Aplikasinya, Cetakan 3. Yogyakarta: Gadjah Mada University Press; 2004.

15. Notoatmodjo Soekidjo. Promosi Kesehatan dan Perilaku. Jakarta: Rineka Cipta Ratu; 2010.

16. Simanjuntak, G.M. Study of Dog Owner Behavior and Opinion with Its Influential Factors toward Rabies Control Programme in Slum Area of Bangkok, Thailand, Faculty of Public Health, Mahidol University, Bangkok,Thailand; 1991.

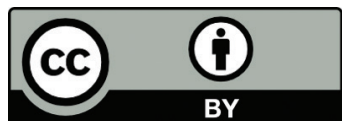

This work is licensed under a Creative Commons Attribution 